\title{
Are Psychiatry Programs Providing Adequate Parental Leave to Their Residents?
}

\author{
France M. Leandre ${ }^{1}\left[\right.$ D $\cdot$ Donna M. Sudak ${ }^{2} \cdot$ Almari Ginory $^{1}$
}

Received: 18 March 2021 / Accepted: 28 October 2021 / Published online: 9 November 2021

(c) Academic Psychiatry 2021

\begin{abstract}
Objective During residency training, parental leave is frequently briefer than may be optimal for the well-being of the family. The Accreditation Council for Graduate Medical Education (ACGME) requires residency programs to have a parental leave policy without providing specific guidelines on its makeup, resulting in varying policies and confusion among residents planning parental leave. This study identifies differences in parental leave policies in psychiatry residencies and discusses if these policies are adequate.

Methods A 45-question, anonymous survey was emailed to general psychiatry and fellowship program directors in the USA. Results Out of 520 program directors contacted, 186 completed the survey (35.7\% response rate). Among the respondents, $94.1 \%$ had policies for maternity leave, $79.8 \%$ had policies for paternity leave, and $67.2 \%$ had policies for non-childbearing parental leave (e.g., adoption). Variations were reported in implementation, coverage, and accommodations. Most respondents $(57.1 \%)$ believed that residents would benefit from more parental leave. Some (11.5\%) believed that parenthood negatively affected residents' overall performance, especially regarding patient care and clinical skills; $36.5 \%$ endorsed that parenthood negatively affected overall residents' well-being; and 7.5\% felt negatively when an applicant was pregnant or was planning to become pregnant during residency. Lastly, 32.9\% were not confident regarding ACGME, American Board of Psychiatry and Neurology, federal, and hospital policies.

Conclusions Parental leave policies are not universal in US psychiatry residency and fellowship programs. Some program directors feel that parenthood adversely affects residents' clinical performance as well as well-being. If true, reformation of parental leave policies may be a remedy.
\end{abstract}

Keywords Parental leave $\cdot$ Residency $\cdot$ Psychiatry $\cdot$ Program directors

Although many studies indicate that the early bond between parents and infants is essential for positive developmental outcomes [1], in the USA, working parents are often required to return to work prematurely [2]. During residency training, parental leave is frequently brief due to pressure from residency programs including rotation requirements, on-call duties, and clinical work. In 2013, the American Academy of Pediatrics recommended residents be provided with at least 6-8 weeks of parental leave regardless of gender [3]. In 2019, most residents reportedly received an average of 6

France M. Leandre

france.leandre@hcahealthcare.com

1 University of Central Florida College of Medicine and HCA Healthcare, Gainesville, FL, USA

2 Drexel University College of Medicine, Philadelphia, PA, USA weeks of paid parental leave, with some receiving less [4, 5]. Fathers and adoptive parents received the least paid leave, at an average of 3 weeks [4]. Furthermore, after returning from leave, residents reported negative bias when evaluated by peers and attendings [6, 7]. Studies have shown that program directors believe becoming a parent negatively affects female trainees' work and increases burdens on fellow residents [8]. Program directors also perceived having children decreases well-being more often in female trainees than in male trainees [8].

The Accreditation Council for Graduate Medical Education (ACGME) requires residency programs to have a parental leave policy in place but has no specific guidelines on its makeup. In 2020, the American Board of Psychiatry and Neurology (ABPN) updated its leave of absence policy to include at least 6 weeks of parental leave without exhausting other leave time or extending training, but a similar policy 
has yet to be incorporated into ACGME guidelines, causing further confusion [9]. In one survey, program directors reported confusion about the rules presented for parental leave policies for residents [10]. Such lack of clarity results in institutions having varying policies and in applicant and resident confusion about options when planning parental leave [11].

Studies on the perspectives of surgical residency program directors about parental leave have occurred [8, 12, 13], but to our knowledge, none have studied the attitudes of psychiatry program directors toward parental leave. Traditionally, psychiatry is perceived as less physically challenging than surgery, but biases against parents, as well as lack of clarity about policies, may still be prevalent. The objectives of this study are to identify differences in parental leave policies among psychiatry residencies, assess whether accommodation is sufficient and within regulations, and suggest ways to improve current policies.

\section{Methods}

A 45-question, anonymous survey created on Qualtrics (Qualtrics, Provo, UT) was emailed to 520 general psychiatry and subspecialty fellowship program directors in the USA from August to October 2020. Email addresses were obtained from the Fellowship and Residency Electronic Interactive Database and the American Association of Directors of Psychiatric Residency Training membership database.

The survey received approval for exempt status from the HCA Healthcare Internal Review Board. Data analysis was conducted on Qualtrics. The survey was developed using similar questions to other studies regarding parental leave in residency programs $[8,12,13]$ and piloted within one training program for any technical errors. The survey was subdivided into multiple sections, including leave policy, attitudes, and demographics.

\section{Results}

A total of $35.7 \%(186 / 520)$ of program directors responded to the survey. Among the respondents, $57.3 \%$ identified as female, $88.5 \%$ were parents, and $61.1 \%$ took personal parental leave during training.

Responses showed variations among parental leave policies (Table 1). Most programs (94.1\%) had maternity leave policies, $79.8 \%$ had paternity leave, and $67.2 \%$ had nonchildbearing parental leave policies. In the following questions, percentages equate to more than $100 \%$ as respondents were allowed to select more than one option. There were differences in access to parental leave policies, some found in a private site (24.3\%), upon request (24.1\%), publicly (19.4\%), in the employment contract (16.5\%), and/or in recruitment material (13.0\%). Lastly, $4.5 \%$ of programs did not have parental leave policies available for review.

Notable differences existed regarding how leave time was allocated. For example, $90.8 \%$ of respondents gave the option of extending the residency, $53.7 \%$ of programs required use of sick or vacation time for parental leave, and $39.3 \%$ allowed residents to take short-term disability. Furthermore, variations existed in the way missed night calls were covered. Among respondents, $48.0 \%$ did not require residents taking parental leave to make up missed call shifts and $64.2 \%$ had other residents cover shifts, $38.8 \%$ had fellows cover, $18.9 \%$ did not need coverage, and $3.0 \%$ hired moonlighters. Moreover, only some programs offered accommodations after residents returned to work; for example, $30.3 \%$ of programs placed residents in a research/elective month, $27.4 \%$ gave the option of working part time, and $17.4 \%$ provided the option of a reduced clinical load. However, $30.3 \%$ offered no accommodations after residents returned to work from parental leave. Additionally, 94.2\% offered accommodations for lactating residents, which varied in that $80.6 \%$ of programs offered a room for pumping breast milk, $67.2 \%$ offered refrigeration for breast milk, and $50.7 \%$ blocked time from duties for pumping breast milk. Only $20.5 \%$ of programs had in-house childcare available.

The questionnaire assessed how program directors evaluated residents once they became parents and if their evaluations differed in relation to gender. Among the responding program directors, $11.5 \%$ believed that parenthood positively affected residents' overall performance in regard to patient care and clinical skills and negatively in scholarly activity and timeliness. Moreover, $72.6 \%$ of respondents did not think that there was a difference in overall performance between men and women taking parental leave; however, $20.1 \%$ thought that men's performance was affected less negatively than the performance of women. Furthermore, $36.5 \%$ believed that parenthood negatively affected overall residents' well-being, versus $46.0 \%$ who believed that parenthood positively affected overall residents' well-being. This opinion did not differ by trainee gender. Lastly, 67.9\% did not think that there was a difference in overall well-being between men and women taking parental leave; however, $21.0 \%$ thought that men were affected less negatively than women.

The best timing for leave was also assessed. Among the responding program directors, $38.8 \%$ considered any year to be reasonable to have children, $35.1 \%$ thought the fourth year of general training was the best due to increased elective time, and $13.3 \%$ believed leave is easier to coordinate during the third (outpatient) year.

A common theme in the comment section was that responding program directors were very supportive of 
Table 1 Program directors' demographics and differences in programs' parental leave $(N=186)$

\begin{tabular}{|c|c|c|}
\hline Variables & $n^{*}$ & $\%$ \\
\hline \multicolumn{3}{|l|}{ Directors' gender } \\
\hline Male & 63 & $40.1 \%$ \\
\hline Female & 90 & $57.3 \%$ \\
\hline \multicolumn{3}{|l|}{ Directors' role } \\
\hline General psychiatry program director & 102 & $65.0 \%$ \\
\hline Fellowship program director & 47 & $29.9 \%$ \\
\hline General psychiatry and fellowship program director & 8 & $5.1 \%$ \\
\hline \multicolumn{3}{|l|}{ Do you have current policies for residents in regard to maternity leave? } \\
\hline Yes & 175 & $94.1 \%$ \\
\hline No & 11 & $5.9 \%$ \\
\hline \multicolumn{3}{|l|}{ Do you have current policies for residents in regard to paternity leave? } \\
\hline Yes & 146 & $79.8 \%$ \\
\hline No & 33 & $18.0 \%$ \\
\hline Not sure & 4 & $2.2 \%$ \\
\hline \multicolumn{3}{|c|}{ Do you have current policies for residents in regard to non-childbearing parental leave (such as adoption leave)? } \\
\hline Yes & 121 & $67.2 \%$ \\
\hline No & 44 & $24.4 \%$ \\
\hline Not sure & 15 & $8.3 \%$ \\
\hline \multicolumn{3}{|l|}{ Are residents who take parental leave required to make up missed call shifts? } \\
\hline Yes, all shifts & 25 & $14.4 \%$ \\
\hline Yes, some shifts & 48 & $27.7 \%$ \\
\hline No & 83 & $48.0 \%$ \\
\hline Not sure & 17 & $9.8 \%$ \\
\hline \multicolumn{3}{|c|}{ If residents cover for co-residents, do residents receive additional financial compensation for coverage for night/weekend calls? } \\
\hline Yes & 2 & $1.2 \%$ \\
\hline No but night/weekend calls are reduced later & 57 & $33.3 \%$ \\
\hline No, residents cover without additional financial compensation or schedule rearrangement & 67 & $39.2 \%$ \\
\hline Not sure & 9 & $5.3 \%$ \\
\hline Residents do not cover for co-residents in my program & 36 & $21.0 \%$ \\
\hline \multicolumn{3}{|l|}{ Where can your parental leave policies be accessed? (Select all that apply**) } \\
\hline Publicly accessible online & 67 & $19.4 \%$ \\
\hline Available on a private site & 84 & $24.3 \%$ \\
\hline Included in employee's contract & 57 & $16.5 \%$ \\
\hline Available upon request & 83 & $24.1 \%$ \\
\hline Included in recruitment materials provided at residency interviews & 45 & $13.0 \%$ \\
\hline They are not available & 9 & $2.6 \%$ \\
\hline
\end{tabular}

*Because not all questions were answered by all participants, the denominator is different for each question

**Percentages equate to more than $100 \%$ as respondents were allowed to select more than one option

residents taking parental leave. In fact, when adding the responses of those who answered that they strongly agree, agree, or somewhat strongly, $57.0 \%$ agreed that trainees could benefit from more parental leave time. Again, when adding those who agreed, $32.8 \%$ endorsed a lack of confidence in knowledge of ACGME, ABPN, hospital, and federal policies, and $25.9 \%$ reported a struggle to find service coverage when trainees take parental leave. Also, 28.5\% stated that insufficient resources exist to provide appropriate parental leave. Lastly, $7.5 \%$ stated they are negatively influenced when applicants are pregnant or plan to become pregnant during residency (Table 2).

\section{Discussion}

Parental leave policies are not uniform in psychiatry residency and fellowship programs in the USA and are variably disseminated. The lack of uniformity and transparency creates challenges for residents and applicants as they 
Table 2 Program director responses to statements regarding parental leave

\begin{tabular}{|c|c|c|c|c|c|c|c|}
\hline Statements & $\begin{array}{l}\text { Strongly } \\
\text { disagree }\end{array}$ & Disagree & $\begin{array}{l}\text { Somewhat } \\
\text { disagree }\end{array}$ & $\begin{array}{l}\text { Neither agree } \\
\text { nor disagree }\end{array}$ & $\begin{array}{l}\text { Somewhat } \\
\text { agree }\end{array}$ & Agree & $\begin{array}{l}\text { Strongly } \\
\text { agree }\end{array}$ \\
\hline $\begin{array}{l}\text { I am negatively influenced when applicants } \\
\text { are pregnant or plan to become pregnant } \\
\text { during residency. }\end{array}$ & $46.0 \%$ & $26.7 \%$ & $5.0 \%$ & $14.9 \%$ & $5.0 \%$ & $2.5 \%$ & $0.0 \%$ \\
\hline $\begin{array}{l}\text { There are insufficient resources to provide } \\
\text { appropriate parental leave. }\end{array}$ & $29.8 \%$ & $18.0 \%$ & $8.7 \%$ & $14.9 \%$ & $14.9 \%$ & $10.6 \%$ & $3.1 \%$ \\
\hline $\begin{array}{l}\text { I struggle to provide service coverage when } \\
\text { my trainees take parental leave. }\end{array}$ & $29.8 \%$ & $23.0 \%$ & $8.7 \%$ & $12.4 \%$ & $19.3 \%$ & $5.0 \%$ & $1.9 \%$ \\
\hline $\begin{array}{l}\text { My trainees could benefit from more parental } \\
\text { leave than given. }\end{array}$ & $3.7 \%$ & $9.9 \%$ & $3.1 \%$ & $26.1 \%$ & $13.7 \%$ & $22.4 \%$ & $21.1 \%$ \\
\hline $\begin{array}{l}\text { I am confident of the ACGME*, ABPN**, } \\
\text { hospital, and federal policies when it comes } \\
\text { to planning parental leave. }\end{array}$ & $3.7 \%$ & $16.1 \%$ & $13.0 \%$ & $15.5 \%$ & $13.0 \%$ & $26.1 \%$ & $12.4 \%$ \\
\hline
\end{tabular}

*Accreditation Council for Graduate Medical Education

**American Board of Psychiatry and Neurology

plan for parental leave. Residents may not be aware of their options if policies are not readily available, and medical students applying for residency training may feel uncertain about asking about such policies for fear of negative ramifications in the selection process. Previous surveys about parental leave indicate that confusion exists because of lack of standardization and open discussion [11].

Transparent policies for potential and existing residents would facilitate open conversations and help residents planning families. Mandatory regulations and detailed suggestions on how to organize parental leave would provide clarity and consistency. This survey confirmed that negative biases exist toward residents who take parental leave. Pressure to return to work prematurely or being in an environment with insufficient support could impact work performance and wellness. New parents may need to recover from pregnancy and delivery and adapt to a different sleep schedule and lifestyle. In one study, residents with greater than 8 weeks of parental leave were less likely to have postpartum depression or burnout and more likely to breastfeed longer, perceive support from colleagues and program directors, and be satisfied with parenthood, but only a few programs provided such leave [14].

Negative biases may not only exist in program directors but also in faculty and co-residents. In another study, surgical residents who took parental leave reported a lack of support from faculty and colleagues [15]. Negative bias may result in poor evaluations [6]. To our knowledge, no survey studies have evaluated co-residents' and faculty members' perspectives on parental leave. The culture of medicine has a history of considering time away from work in a negative light, however, and the need to increase workload to cover for an absent resident is likely to produce negative attitudes.
Our study has several limitations and survey biases. The response rate is lower than some previously published studies, with responses around $60.0 \%$ compared to this study's $35.7 \%[8,12,13]$. The survey was sent during the COVID-19 pandemic, which could have affected the response rate. Moreover, participation bias may have played a factor because program directors holding more negative biases about residents' parental leave may have been less willing to respond. Social desirability bias may have been present as program directors might have answered in a way that is more favorable to themselves or their program. Despite these limitations, the responses identified gaps and disparities between programs and directors.

While some progress toward uniform standards of parental leave has been made by organizations such as ABPN, there is not yet a standard in psychiatry residencies for such an important time away from work. A universal parental leave policy available to all psychiatry program directors and residents would result in uniformity and fairness. A clearly delineated plan would resolve ambiguity, increase residents' confidence about starting a family, and decrease potential biases. In addition, educating staff about the importance of parental leave may help alleviate biases between genders and about the leave itself.

Acknowledgements This research was supported (in whole or in part) by HCA Healthcare and/or an HCA Healthcare affiliated entity.

\section{Declarations}

Disclosures On behalf of all authors, the corresponding author states that there is no conflict of interest. 
Disclaimer The views expressed in this publication represent those of the author(s) and do not necessarily represent the official views of HCA Healthcare or any of its affiliated entities.

\section{References}

1. Plotka R, Busch-Rossnagel N. The role of length of maternity leave in supporting mother-child interactions and attachment security among American mothers and their infants. Int J Child Care Educ Policy. 2018;12(1):2.

2. Burtle A, Bezruchka S. Population health and paid parental leave: what the United States can learn from two decades of research. Healthcare. 2016;4(2):30.

3. Section on Medical Students, Residents, and Fellowship Trainees Committee on Early Childhood. Parental leave for residents and pediatric training programs. Pediatrics. 2013;131(2):387-390.

4. Vogel L. Starting a family during residency? Leave policies complicate the choice. CMAJ. 2019;191(5):E146-7.

5. Stack S, Jagsi R, Biermann J, Lundberg G, Law K, Milne C, et al. Maternity leave in residency. Acad Med. 2019;94(11):1738-45.

6. Krause M, Elrashidi M, Halvorsen A, McDonald F, Oxentenko A. Impact of pregnancy and gender on internal medicine resident evaluations: a retrospective cohort study. J Gen Intern Med. 2017;32(6):648-53.

7. Mulcahey M, Nemeth C, Trojan J, O'Connor M. The perception of pregnancy and parenthood among female orthopaedic surgery residents. J Am Acad Orthop Surg. 2019;27(14):527-32.

8. Sandler B, Tackett J, Longo W, Yoo P. Pregnancy and parenthood among surgery residents: results of the first nationwide survey of general surgery residency program directors. J Am Coll Surg. 2016;222(6):1090-6.

9. American Board of Psychiatry and Neurology. Policies - American Board of Psychiatry and Neurology. [online]. 2021. Available at: https://www.abpn.com/about/policies/. Accessed 11 May 2021.

10. Gracey L, Cronin M, Shinkai K, Mathes E. Program director and resident perspectives on new parent leave in dermatology residency. JAMA Dermatol. 2018;154(10):1222.

11. Augustine H, Rizvi S, Dunn E, Murphy J, Retrouvey H, Efanov $\mathrm{J}$, et al. Pregnancy and parental leave among plastic surgery residents in Canada: a nationwide survey of attitudes and experiences. Can J Surg. 2020;63(5):E454-9.

12. Hariton E, Matthews B, Burns A, Akileswaran C, Berkowitz L. Pregnancy and parental leave among obstetrics and gynecology residents: results of a nationwide survey of program directors. Am J Obstet Gynecol. 2018;219(2):199.e1-8.

13. Nemeth C, Roll E, Mulcahey M. Program directors' perception of pregnancy and parenthood in orthopedic surgery residency. Orthopedics. 2020;43(2):e109-13.

14. Stack SW, McKinney CM, Spiekerman C, Best JA. Childbearing and maternity leave in residency: determinants and well-being outcomes. Postgrad Med J. 2018;94(1118):694-9.

15. Altieri MS, Salles A, Bevilacqua LA, Brunt LM, Mellinger JD, Gooch JC, et al. Perceptions of surgery residents about parental leave during training. JAMA Surg. 2019;154(10):952.

Publisher's Note Springer Nature remains neutral with regard to jurisdictional claims in published maps and institutional affiliations. 